\title{
Effect of Chemical Treatment on the Degree of Deacetylation of Chitosan
}

\section{Atanda SA*, Agboola AA, Udefi IO, Fapohunda TB and Nnamani J}

Nigerian Stored Products Research Institute, Nigeria

*Corresponding author: Atanda Saburi Abimbola, Nigerian Stored Products Research Institute 32/34 Barikisulyede Street off University Road Yaba, PMB 12543 Lagos, Nigeria, E-mail: abimbola91@yahoo.com

\section{Research Article}

Volume 1 Issue 2

Received Date: October 11, 2016

Published Date: November 17, 2016

DOI: $10.23880 /$ NNOA-16000110

\section{Abstract}

Chitosan wide range of application is highly dependent mainly on the presence of the reactive amino groups and its degree of deacetylation (DDA) is one of the main parameters characterizing chitosan. Chitosan was produced from deacetylation of chitin using $70 \%$ alkali concentration in an autoclave at $120^{\circ} \mathrm{C}$ for 1 hour. The degree of deacetylation (DDA) was determined using the acid-base titration method. A degree of deacetylation (DDA) of 70.67\% was achieved from the autoclave synthesized chitosan compared to the conventional synthesized chitosan using a lower alkali concentration and temperature with a degree of deacetylation of $62.36 \%$. In conclusion, the use of autoclave and increasing alkali concentration increased the DDA and may possibly influence other functional and biological properties of chitosan.

Keywords: chitosan; chitin; degree of deacetylation; amino group

\section{Introduction}

Chitosan is a polysaccharide usually obtained from deacetylation of chitin, which after cellulose is the second most abundant natural biopolymer found in nature. It may be extracted from various sources, particularly from exoskeletons of arthropods of crustaceans, fungi, insects, annelids, mollusks and coelenterate. The structures of chitin and chitosan correspond to those of poly $[\beta(1 \rightarrow 4)$ 2 -acetamide-2-deoxy-d-glucopyranose] and poly $[\beta$ $(1 \rightarrow 4)$-2-amino-2-deoxy-d-glucopyranose], respectively [1]. The homopolymer is a weak base with a $\mathrm{pKa}$ value of the d-glucosamine residue of about $6.2-7.0$ and is therefore insoluble at neutral and alkaline $\mathrm{pH}$ values. In acidic medium, the amine groups will be positively charged, conferring to the polysaccharide a high charge density. Due to its polycationic nature, chitosan, after being dissolved in aqueous acid solutions, can be easily molded and used as membranes, beads, microparticles and gels [2]. Also, its functional properties such as biodegradability and low toxicity $[3,4]$ have driven the research and applications of chitosan to medicine $[2,5,6]$, food additives and preservatives [7], agriculture including coating of fertilizers, pesticides, herbicides, and insecticides for their controlled release to soil and also coating of seeds and leaves to prevent microbial infections [8] as well as in the paper industry and for the treatment of industrial wastewater [9].

Chitosan is the form of chitin which has been deacetylated to at least $50 \%$ of the free amine form, which 


\section{Nanomedicine \& Nanotechnology Open Access}

has a heterogeneous chemical structure made up of both 1-4 linked 2-acetamido-2-deoxy- $\beta$-D-glucopyranose as well as 2 -amino-2-deoxy- $\beta$-Dglucopyranose [10].

The degree of deacetylation controls the amount of free amino groups in the polymer chain. The free amino groups give chitosan its positive charge. The degree of deacetylation (DDA) influences the physical, chemical and biological properties of chitosan, such as acid base and electrostatic characteristics, biodegradability, selfaggregation, sorption properties and the ability to chelate metal ions. In addition, the degree of deacetylation, which determines the content of free amino groups in the polysaccharide [11], can be employed to differentiate between chitin and chitosan. There are various methods available to increase or decrease the degree of deacetylation. An increase in either temperature or strength of sodium hydroxide solution can enhance the removal of acetyl groups from chitin, resulting in a range of chitosan molecules with different properties and hence its applications [12]. Different conditions such as type and concentration of reagents, time and temperature employed throughout the processing can affect the physical characteristics and performance of the final chitosan product [13]. The objective of this study was to synthesize chitosan using an autoclave as a reaction vessel with a higher alkali concentration in order to reduce the deacetylation time and increase the DDA.

\section{Materials and Methods}

\section{Reagents}

The following chemical were used as received: Sodium hydroxide and hydrochloric acid (BDH, Poole, England); liquid paraffin and acetone (Analar, Essex, England).

\section{Experimental}

\section{Preparation of Chitosan (A)}

Snail shells obtained were washed thoroughly with distilled water and air dried for 3 days. $50 \mathrm{~g}$ of the finely grinded sample was taken for the deproteinization extraction process involving addition of $10 \mathrm{M}$ sodium hydroxide $(40 \% \mathrm{w} / \mathrm{v})$ in an autoclave at $120^{\circ} \mathrm{C}$ for 1 hour at a pressure of 15 pound per square inch. The resulting residue was washed with deionised water to bring the $\mathrm{pH}$ to neutral. The neutral residue was then dried at $100^{\circ} \mathrm{C}$ for 1 hour. The dry residue was demineralised by adding $100 \mathrm{~cm}^{3} 1 \mathrm{M}$ hydrochloric acid was placed in an autoclave at $80^{\circ} \mathrm{C}$ for 45 minutes until no bubbles were observed. It was washed repeatedly with deionised water to a neutral $\mathrm{pH}$ and dried at $90^{\circ} \mathrm{C}$ for 1 hour. The dry powder was decolourised by refluxing in $75 \mathrm{~cm}^{3}$ acetone in a paraffin wax bath at $60^{\circ} \mathrm{C}$ for 3 hours on a magnetic stirrer to give a near white powder. The near white powder was air dried in ambient condition and screened with $150 \mu \mathrm{m}$ sieve. The powder was finally deacetylated with $100 \mathrm{~cm}^{3}$ $17.5 \mathrm{M}(70 \% \mathrm{w} / \mathrm{v})$ sodium hydroxide solution in an autoclave at $120^{\circ} \mathrm{C}$ for 1 hour at a pressure of 15 pound per square inch. After deacetylation, the chitosan was then washed thoroughly with deionized water to a neutral $\mathrm{pH}$, dried at $90^{\circ} \mathrm{C}$ for 1 hour and kept inside a polythene container for storage. The synthesized was based on the procedure of [14] Adewuyiet al., with modification.

\section{Preparation of Chitosan (B)}

Snail shells obtained were washed thoroughly with distilled water and air dried for 3 days. $50 \mathrm{~g}$ of the finely grinded sample was taken for the deproteinization extraction process involving addition of $10 \mathrm{M}$ sodium hydroxide $(40 \% \mathrm{w} / \mathrm{v})$ at $80^{\circ} \mathrm{C}$ for 6 hours on a magnetic stirrer. The resulting residue was washed with deionised water to bring the $\mathrm{pH}$ to neutral. The neutral residue was then dried at $100^{\circ} \mathrm{C}$ for 1 hour. The dry residue was demineralised by adding $100 \mathrm{~cm}^{3} 1 \mathrm{M}$ hydrochloric acid. Effervescence occurred due to the liberation of carbon dioxide hours at $30^{\circ} \mathrm{C}$ for 3 hours on a magnetic stirrer. The sample was then washed with distilled water until a relatively neutral was obtained and then the demineralized shell was dried to constant weight. The demineralized residue was decolourised by refluxing in $75 \mathrm{~cm}^{3}$ acetone in a paraffin wax bath at $60^{\circ} \mathrm{C}$ for $3 \mathrm{~h}$ on a magnetic stirrer to give a near white powder. The near white powder was air dried in ambient condition and screened with $150 \mu \mathrm{m}$ sieve. The chitin powder was finally deacetylated with $80 \mathrm{~cm}^{3} 12.5 \mathrm{M}$ sodium hydroxide solution under constant stirring on a magnetic stirrer at $30^{\circ} \mathrm{C}$ for 4 hours. After deacetylation, the chitosan was then washed thoroughly with deionized water to a neutral $\mathrm{pH}$, dried at $90^{\circ} \mathrm{C}$ for 1 hour and kept inside a polythene container for storage [14].

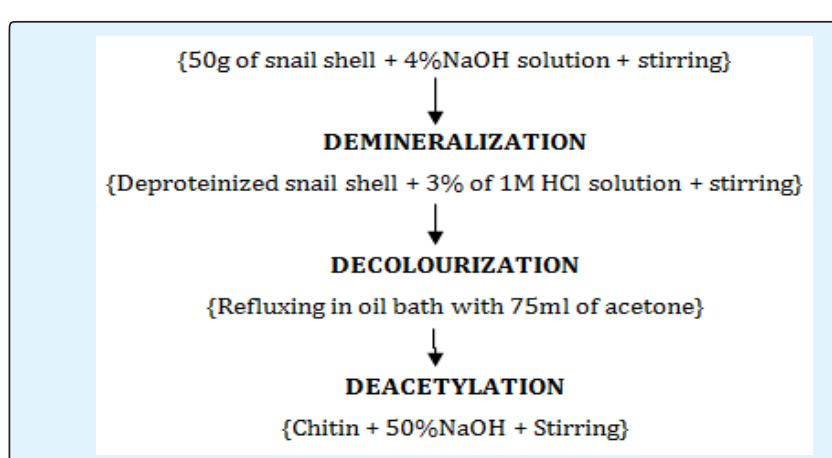

Figure 1: Schematic Process for the Production of Chitosan. 


\section{Nanomedicine \& Nanotechnology Open Access}

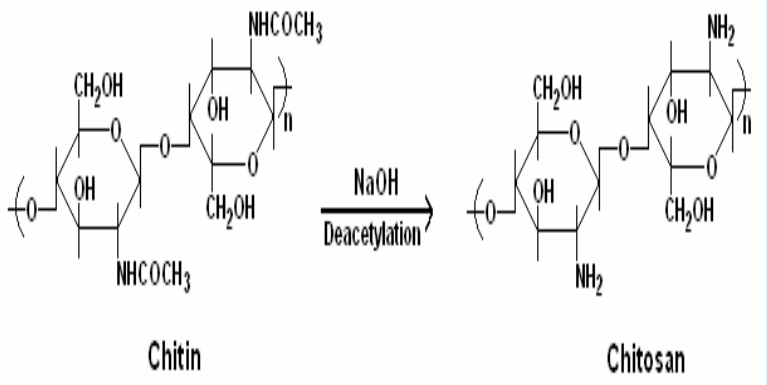

Figure 2: Deacetylation of Chitin to Chitosan.

\section{Characterization of chitosan}

Determination of degree of deacetylation: Chitosan of $0.125 \mathrm{~g}$ was dissolved in $25 \mathrm{~cm}^{3}$ aqueous solution $0.1 \mathrm{~mol}$ per $\mathrm{dm}^{3}$ hydrochloric acid. The content of the flask was stirred for 30 minutes until it dissolved totally. The solution was titrated with 0.1 mol per $\mathrm{dm}^{3}$ sodium hydroxide. The amount of amino group was calculated as follow:

$$
\mathrm{NH}_{2}(\%)=\underline{G} \underline{G} \frac{\mathrm{C}_{1}}{\mathrm{~V}_{1}}-\frac{\mathrm{C}_{2}}{2} \underline{\mathrm{V}_{2}} \times 0.016
$$

Where:

$\mathrm{C}_{1}$ - concentration of standard $\mathrm{HCl}$ aqueous solution

$\mathrm{C}_{2}$-standard $\mathrm{NaOH}$ solution

$\mathrm{V}_{1}$ - Volume of the standard $\mathrm{HCl}$ aqueous solution used to dissolve chitosan ( $\mathrm{ml}$ )

$\mathrm{V}_{2}$ - Volume of standard $\mathrm{NaOH}$ solution consumed during titration (ml)

G- Weight of chitosan (g)

W- Water percentage of chitosan

The number $0.016(\mathrm{~g})$ is the equivalent weight of $\mathrm{NH}_{2}$ group in $1 \mathrm{ml}$ of standard $1 \mathrm{~mol} / \mathrm{LHCl}$ aqueous solution

DDA $(\%)=\mathrm{NH}_{2}(\%) / 9.94 \% \times 100 \%$.

$9.94 \%$ is the proportion of $\mathrm{NH}_{2}$ group by weight in chitosan.

\section{Infra-Red Spectrophotometry}

Dry samples of chitosan obtained by the two procedures were prepared for IR analysis by making slurry with hydrocarbon oil (NUJOL). The slurry was then transferred to a $\mathrm{NaCl}$ plate and inserted into the sample compartment. Infrared spectra depicting the functional groups were obtained using Buck Demo 500 spectrophotometer by recording 45 scan in $\% \mathrm{~T}$ mode in the range of $4000 \pm 200 \mathrm{~cm}^{-1}$.

\section{Results and Discussion}

The mean values of degree of deacetylation of the two sets of chitosan are presented in (Tables 1,2). For chitosan (A), obtained using an autoclave and higher alkali concentration, the values range between $70.67 \%$ $69.70 \%$ and are not significantly different from one another while chitosan (B), obtained using a magnetic stirrer and lower alkali concentration the values range between $62.36 \%-61.50 \%$ and also not significantly different from one another ( $p>0.05)$. As expected, DDA from the autoclave process are higher than the magnetic stirrer synthesized chitosan as shown from Table 1 and 2. However, the time taken for the deacetylation process with the use of an autoclave was lower than the time taken for the same process without the use of an autoclave i.e. using a magnetic stirrer.

(Table 3) shows the various functional groups and the bands at which they appear in the two sets of chitosan. The band obtained at $3500 \mathrm{~cm}^{-1}$ and $3000 \mathrm{~cm}^{-1}$ attributed to the stretching mode of hydroxyl and extension vibration of $\mathrm{N}-\mathrm{H}$ which is a broad and strong band in chitosan (A). The broad peak is due to inter- and intramolecular hydrogen bonds. The band at $2945 \mathrm{~cm}^{-1}$ represents stretching $\mathrm{N}-\mathrm{H}$ in amine. Lower intensity peak at $2743 \mathrm{~cm}^{-1}$ are assigned to the symmetric and asymmetric modes of $\mathrm{CH}_{2}$ group vibrations. This shows that chitosan (A) contained a free amino group that defines a chitosan. The peak observed at $1461 \mathrm{~cm}^{-1}$ and $1379 \mathrm{~cm}^{-1}$ are characteristic of chitosan as amine I and amide II peaks respectively. The absorption band featuring bending vibration of $\mathrm{NH}$ from $\mathrm{R}^{-\mathrm{NH}_{2}}$ was observed at $1795 \mathrm{~cm}^{-1}$ indicating increase degree of deacetylation. This was compared with the result obtained by [15] Teli and Sheikh and a degree of similarity was observed. The band near $3450 \mathrm{~cm}^{-1}$ representing $\mathrm{OH}$ stretching becomes broader with lower intensity as it has undergone $\mathrm{N}$-deaectylation and supported with the result of [16]Zhang et al. [17] Pawlak and Mucha reported that a band at $3360 \mathrm{~cm}^{-1}$ which represents the stretching $-\mathrm{NH}_{2}$ in amine group. This shows the existence for free amino group present in chitosan. The peak at $1080 \mathrm{~cm}^{-1}$ is characteristic of C-O stretching vibration. The absorption band at $1080 \mathrm{~cm}^{-1}$ and $856 \mathrm{~cm}^{-1}$ corresponds to the characteristic absorption bands of $\mathrm{C}=0$ group of amide I and of $\beta$-D-glucose unit respectively. Meanwhile, extra bands in the region of $1605 \mathrm{~cm}^{-1}-1566 \mathrm{~cm}^{-1}$ was reported due to amine group where $3450 \mathrm{~cm}^{-1}, 3262 \mathrm{~cm}^{-1}, 3114 \mathrm{~cm}^{-1}$ and $1658 \mathrm{~cm}^{-1}$ were missing due to amide group withdrew during deacetylation. This indicates that chitin is transform to chitosan through n-deacetylation which reduce the amide 


\section{Nanomedicine \& Nanotechnology Open Access}

content. This is observed as the reductions of band at $1655 \mathrm{~cm}^{-1}$ as it transformed from chitin to chitosan. In Figure 3 and 4, the absorption bands used to distinguish protein $\left(1540 \mathrm{~cm}^{-1}\right)$ and mineral $\left(1798 \mathrm{~cm}^{-1}, 1420 \mathrm{~cm}^{-1}\right.$ $1430 \mathrm{~cm}^{-1}$ and $876 \mathrm{~cm}^{-1}$ ) are not observed in the spectrum of chitosan (A) compared to chitosan (B) This shows the effectiveness of the deproteinisation and demineralization steps using an autoclave and higher alkali concentration.

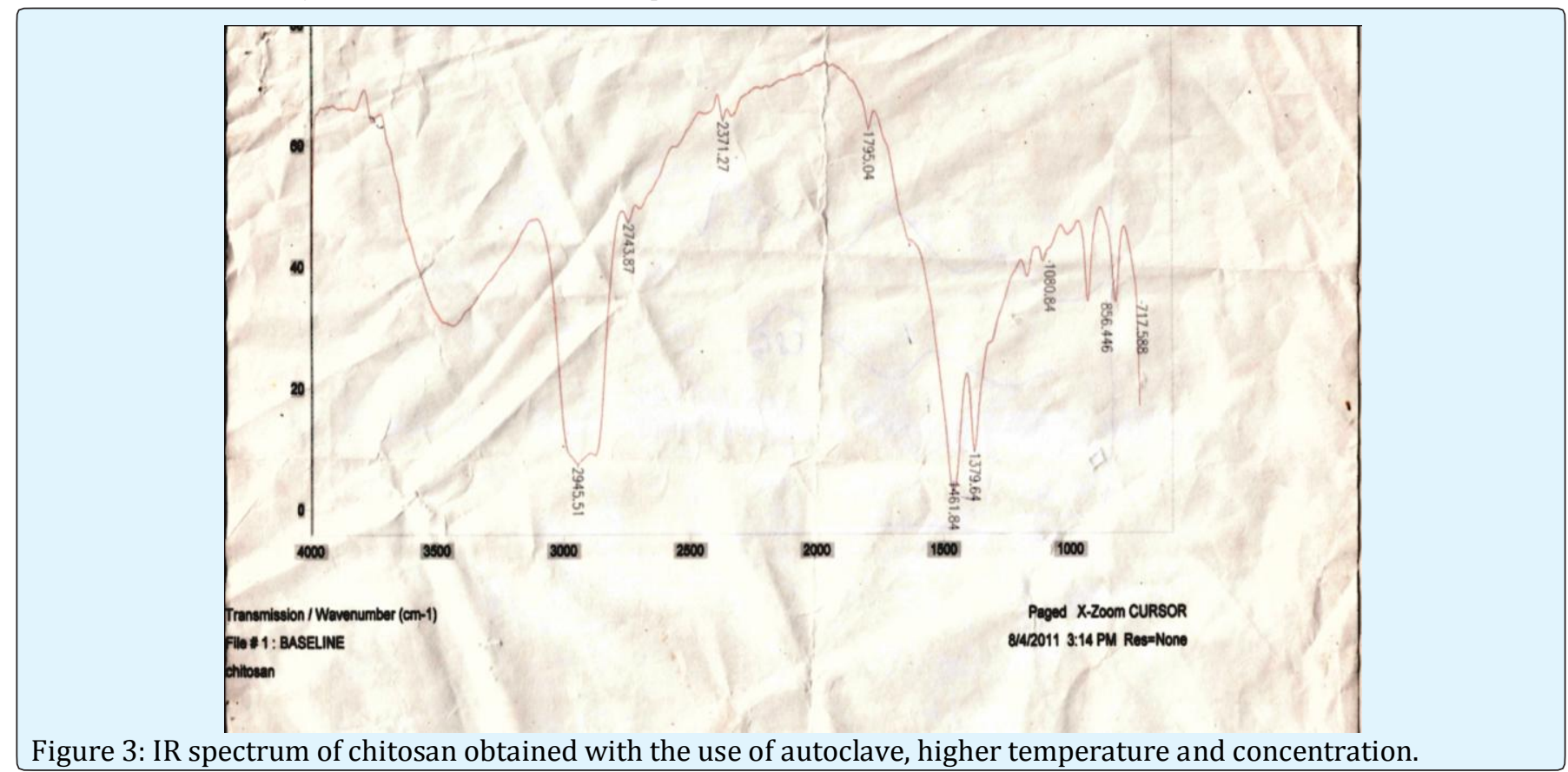

Figure 3: IR spectrum of chitosan obtained with the use of autoclave, higher temperature and concentration.

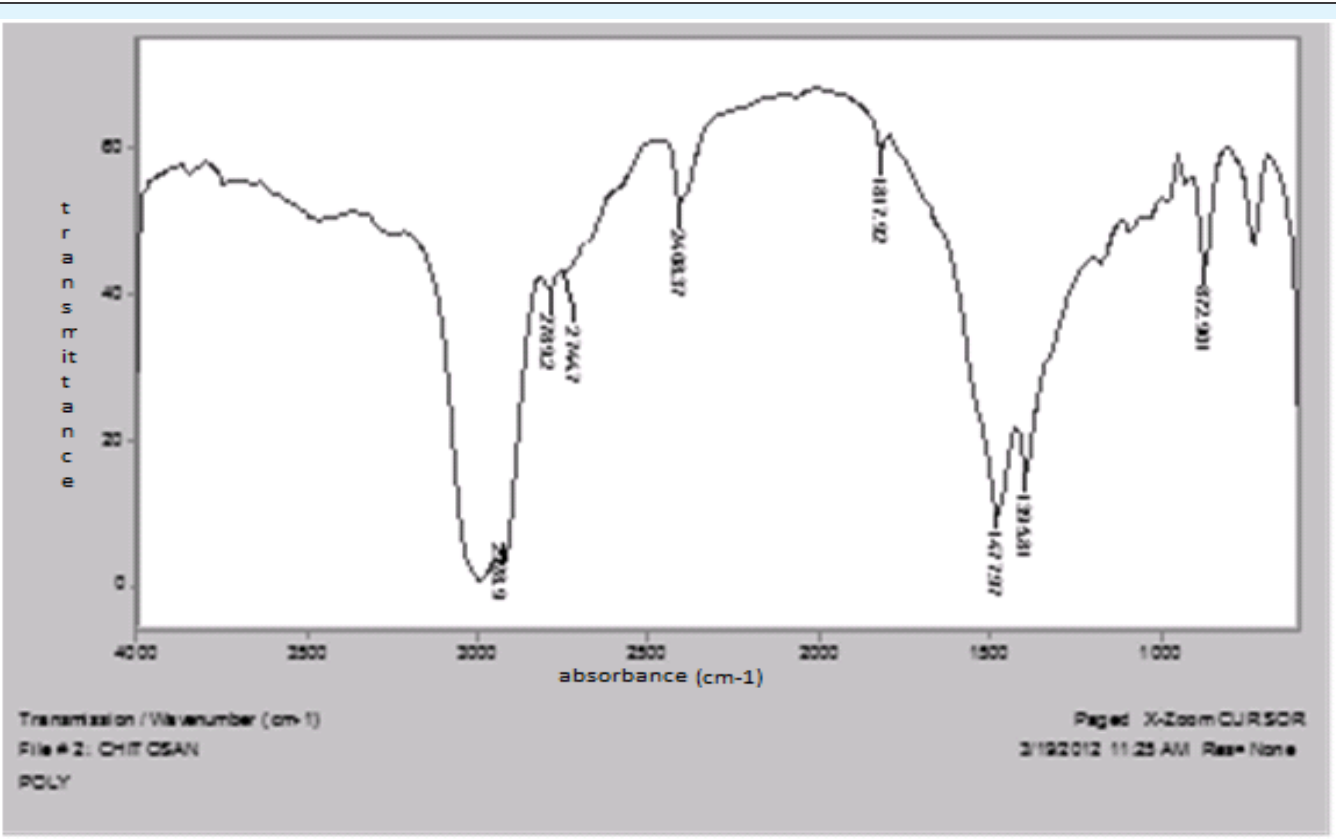

Figure 4: IR spectrum of chitosan obtained without the use of autoclave, lower temperature and concentration.

(Table 3) shows a broad peak at $3000 \mathrm{~cm}^{-1}$, the broad bands in the region of $3000-3600 \mathrm{~cm}^{-1}$ is attributed to the overlapping stretching of $\mathrm{O}-\mathrm{H}$ groups and amine $\mathrm{N}-\mathrm{H}$ symmetrical vibration in chitosan (B). The high intensity 


\section{Nanomedicine \& Nanotechnology Open Access}

peak at $2789 \mathrm{~cm}^{-1}$ and the lower intensity peak at $2928 \mathrm{~cm}^{-}$ ${ }^{1}$ are assigned to the symmetric and asymmetric modes of $\mathrm{CH}_{2}$ group vibrations. Strong absorption peaks at 1477 and $1395 \mathrm{~cm}^{-1}$ are characteristic of chitosan and have been reported as amine I and amide II peaks respectively. The first peak for chitosan at $898 \mathrm{~cm}^{-1}$ is assigned to the ether linkage $\mathrm{C}-\mathrm{O}-\mathrm{C}$ structure and carbonyl stretching occurring at $1819 \mathrm{~cm}^{-1}$. Similar reports have been reported by [18]Saifuddin et al.

A

\begin{tabular}{|c|c|}
\hline S/N & Degree of Deacetylation (\%) \\
\hline 1 & $69.70 \pm 0.62^{\mathrm{a}}$ \\
\hline 2 & $70.67 \pm 0.90^{\mathrm{a}}$ \\
\hline 3 & $70.30 \pm 0.03^{\mathrm{a}}$ \\
\hline
\end{tabular}

Table 1: Values of degree of deacetylation of chitosan produced with the use of autoclave and th higher alkali concentration $(\mathrm{n}=3)$. Values are not significantly different $\mathrm{p}>0.05$.

B

\begin{tabular}{|c|c|}
\hline S/N & Degree of Deacetylation (\%) \\
\hline 1 & $61.50 \pm 0.72^{\mathrm{a}}$ \\
\hline 2 & $62.07 \pm 0.80^{\mathrm{a}}$ \\
\hline 3 & $62.36 \pm 0.03^{\mathrm{a}}$ \\
\hline
\end{tabular}

Table 2: Values of degree of deacetylation of chitosan produced without the use of autoclave with lower alkali concentration $(n=3)$ Values are not significantly different $\mathrm{p}>0.05$.

\begin{tabular}{|c|c|c|}
\hline Functional group & Chitosan (A) & Chitosan (B) \\
\hline $\begin{array}{c}\text {-OH- and -NH } \\
\text { Vibrations }\end{array}$ & $3500 \mathrm{~cm}^{-1}$ & $3000 \mathrm{~cm}^{-1}$ \\
\hline -COO- & - & - \\
\hline Carbonyl Streching & $1795 \mathrm{~cm}^{-1}$ & $1819 \mathrm{~cm}^{-1}$ \\
\hline $\begin{array}{c}\text { AmideI and II } \\
\text { bands }\end{array}$ & $\begin{array}{c}1461 \mathrm{~cm}^{-1} \text { and } \\
1379 \mathrm{~cm}^{-1}\end{array}$ & $\begin{array}{c}1477 \mathrm{~cm}^{-1} \\
\text { and } 1395 \mathrm{~cm}^{-1}\end{array}$ \\
\hline $\begin{array}{c}\text { Symmetric } \mathrm{CH}_{2} \\
\text { vibration }\end{array}$ & $2945 \mathrm{~cm}^{-1}$ & $2928 \mathrm{~cm}^{-1}$ \\
\hline $\begin{array}{c}\text { Asymmetrc } \mathrm{CH}_{2} \\
\text { vibration }\end{array}$ & $2743 \mathrm{~cm}^{-1}$ & $2789 \mathrm{~cm}^{-1}$ \\
\hline $\begin{array}{c}\text { C-O-C } \\
\text { Ether lnkage }\end{array}$ & $856 \mathrm{~cm}^{-1}$ & $899 \mathrm{~cm}^{-1}$ \\
\hline
\end{tabular}

Table 3: Various functional groups and their wavelengths obtained from chitosan (A and B).

\section{Conclusion}

The use of an autoclave at a temperature of $130^{\circ} \mathrm{C}$ with $70 \%$ alkali concentration in chitosan synthesis gave a higher degree of deacetylation compared to chitosan synthesized using the conventional method. However, additional studies are needed to verify the effect of these operating conditions on the functional and chemical properties of chitosan to enhance its uses. Also more accurate method of determining degree of deacetylation such as nuclear magnetic resonance spectroscopy (NMR), enzymatic determination, infrared spectroscopy (IR) etc. need to be examined.

\section{Acknowledgement}

The authors are grateful to gratitude goes to Mr. Bello T.0. of Chemistry Department University of Lagos for his effort during the research work.

\section{References}

1. Ravi KMN, Muzzarelli RA, Muzzarelli C, Sashiwa H, Domb AJ (2004) Chitosan; Chemistry and Pharmaceutical Perspectives. Journal Chem Rev 104(12): 6017-6084.

2. Rinaudo M (2006) Chitin and chitosan: properties and applications. Progress in Polymer Science 31(7): 603-632.

3. Domard A (2011) A perspective on 30 years research on chitin and chitosan. Carbohydrate Polymers 84(2): 696-703.

4. Kean T, Thanou M (2010) Biodegradation, biodistribution and toxicity of chitosan. Adv Drug Deliver Rev, 62(1): 3-11.

5. Shi CM, Zhu Y, Ran X, Wang M, Su Y, et al. (2006) Therapeutic potential of chitosan and its derivatives in regenerative medicine. J Surg Res 133(2): 185-192.

6. Jayakumar R, Prabaharan M, Sudheesh Kumar PT, Nair SV, Tamura H (2011) Biomaterials based on chitin and chitosan in wound dressing applications. Biotechnol Adv 29(3): 322-337. 


\section{Nanomedicine \& Nanotechnology Open Access}

7. Shahidi F, Arachchi JKV, Jeon YJ (1999) Food applications of chitin and chitosan. Trends in Food Science \& Technology 10(2): 37-51.

8. Krajewska B (2004) Application of chitin- and chitosan-based materials for enzyme immobilizations: a review. Enzyme and Microbial Technology 35(2-3): 126-139.

9. Ngah WSW, Teong LC, Hanafiah MAKM (2011) adsorption of dyes and heavy metal ions by chitosan composites: a review. Carbohydrate Polymers 83(4): 1446-1456.

10. Hudson SM, Jenkins DW (2001) Chitin and Chitosan in Encyclopedia of Polymer Science and Technology. Wiley Interscience.

11. Sun Ok, FKBS (2004) Physicochemical and functional properties of crawfish chitosan as affected by different processing protocols. A Thesis Submitted to the Graduate Faculty of the Louisiana State University and Agricultural and Mechanical College in partial fulfillment of the requirements for the degree of Master of Science in The Department of Food Science Seoul National University, 1991.(In) Li, Q., Dunn, E.T.,

12. Grandmaison EW, Goosen MFA (1992) Applications and properties of chitosan. Journal of Bioactive and Compatible Polymers 7: 370-397.
13. Sridhar S, Susheela G, Jayasimha G, Khan AA (2001) Crosslinked chitosan membrane: characterization and study of dimethly hydrazine dehydration by preparation. Society of Chemical Industry 50: 11561161.

14. Adewuyi S, Akinhanmi TF, Taiwo E0, Adeyemi (2008) Chelation of Zinc (II) Metal ion (II) ion from waste water with Biopolymeric Chitosan Ligand produced from snail shell. J of Chem Soc of Nig 33(2): 46-49.

15. Teli MD, Sheikh J (2012) Extraction of chitosan from shrimp shells waste and application in antibacterial finishing of bamboo rayon. International Journal of Biological Macromolecules 50(5): 1195-1200.

16. Zhang Y, Xue C, Li Z, Zhang Y, Fu X (2006) Preparation of halfdeacetylated chitosan by forced penetration and its properties. Carbohydrate Polymers 65(3): 229-234.

17. Pawlak A, Mucha M (2003) Thermogravimetric and FTIR studies of chitosan blends. Thermochimica Acta 396(1-2): 153-166.

18. Saifuddin N, Nian CY, Zhan LW, Ning KX (2011) Chitosan-silver nanoparticles composite as point-ofuse drinking water filtration system for household to remove pesticides in water. Asian Journal of Biochemistry 6: 142-159. 